\title{
Natural Killer Cells: A Potential Therapy for Paediatric Brain Tumours
}

\author{
Coral Fairhead ${ }^{1}$, Hisaki Fujii' ${ }^{1,2}$, Zhi-Juan Luo ${ }^{1}$, Hye Jin Kim ${ }^{1}$ and R Maarten Egeler ${ }^{1,2^{*}}$ \\ ${ }^{1}$ Developmental and Stem Cell Biology Program, The Hospital for Sick Children, Toronto, ON, Canada \\ ${ }^{2}$ Section Stem Cell Transplantation, Division Haematology/Oncology, The Hospital for Sick Children/University of Toronto, Toronto, Canada
}

*Corresponding author: Egeler RM, MD/PhD, Developmental and Stem Cell Biology Program, Section Stem Cell Transplantation, Division Haematology/Oncology, The Hospital for Sick Children, 555 University Avenue, Toronto, ON M5G 1X8 Canada, Tel: 416-813-7654 ; Fax: 416-813-5327; E-mail: maarten.egeler@sickkids.ca

Received date: Oct 08, 2014, Accepted date: Dec 26, 2014, Published date: Dec 30, 2014

Copyright: ( 2014 Fairhead C, et al. This is an open-access article distributed under the terms of the Creative Commons Attribution License, which permits unrestricted use, distribution, and reproduction in any medium, provided the original author and source are credited.

\begin{abstract}
Natural killer cells are innate immune cells that are naturally involved in tumour immunosurveillance. These cells have direct cytotoxic activity and also secrete proinflammatory cytokines upon activation. The activation of natural killer cells' cytolytic activity is dependent on a balance between inhibitory signals and activating signals provided by the host cells. Natural killer cells do not exert their activity on healthy cells, due to interactions of inhibitory receptors with self major histocompatibility class I. Inhibition may be overcome when the cell binds tumour-associated antigens on the surface of tumour cells, resulting in the polarized release of cytolytic granules toward the target cell. Natural killer cells demonstrate particular promise for cellular therapy, as they can identify and eliminate tumours that have altered major histocompatibility class I expression. Central nervous system tumours are the second most common paediatric cancer and are associated with a high mortality rate. Many of these high-grade paediatric brain tumours have very dismal prognoses, despite standard treatment regimens, and patients would substantially benefit from a novel type of therapy. Natural killer cells have been shown to be effective against many human malignancies; however, less is known about their efficacy against brain tumours. Treatment of medulloblastoma and adult glioblastoma with natural killer cells has been investigated previously and yielded promising results. Natural killer cells represent a small fraction of peripheral blood, which poses a limitation for their widespread use in adoptive cell therapy. Current research is focussed on establishing an optimal protocol for the ex vivo expansion and activation of natural killer cells. In the future, paediatric brain tumours such as glioblastoma multiforme, ependymoma and atypical teratoid/rhabdoid tumours should be examined for their susceptibility to natural killer cells.
\end{abstract}

Keywords: Natural killer (NK) cells; Immunotherapy; Paediatric brain tumours

\section{Introduction}

Tumours of the central nervous system (CNS) are the second most frequent childhood malignancy following leukaemia, and are associated with a high mortality rate $[1,2]$. Contrary to the belief that the incidence of paediatric CNS tumours has reached a plateau, they are increasing in frequency annually [1]. The amelioration and development of novel diagnostic techniques cannot fully explain this trend [1,3]. Per 100,000 children worldwide per year, 11 new CNS tumour diagnoses are made [1]. For many high-grade malignant brain tumours there is no permanent cure and there can be harmful side effects from treatment including surgery, chemotherapy and/or radiation therapy [4-7]. It is difficult to establish one effective treatment for all brain tumours because of their histological heterogeneity and therefore their susceptibility to different forms of therapy may be highly variable. For example, glioblastomas are frequently chemotherapy-resistant [7]. It is clear that significant research efforts need to be focussed on novel cancer therapeutics for brain tumour patients. Cell-based therapies are becoming increasingly popular for the treatment of human malignancies. Natural killer (NK) cells are particularly promising for use in adoptive cellular therapies due to their natural involvement in tumour immunosurveillance, their broad target cell range, and the added benefit that they do not cause the debilitating Graft versus Host Disease [8-10]. In this review, we discuss the function of NK cells and their potential for use in the treatment of paediatric brain tumours.

\section{Paediatric Brain Tumours}

Medulloblastoma is the most common malignant brain tumour of childhood, comprising $18 \%$ of all cases [11,12]. It is a highly aggressive small blue cell tumour occurring in the posterior fossa $[13,14]$. Medulloblastoma is the most prevalent tumour of the CNS that causes extraneural metastasis [11]. With standard of care, survival is $60-80 \%$ at 5 years following initial diagnosis [15]; however, younger patients do not see such a good prognosis [14]. Recently, four distinct subgroups have been identified on the basis of demographics, transcriptomes, somatic mutations and clinical outcomes [13]. The Wnt and Sonic Hedgehog (Shh) subgroups are so named due to the involvement of their respective signalling pathways [13]. The Wnt subgroup is uncommon in infants, but is more common in children and adults [13]. This subgroup has a good long-term prognosis with survival rates surpassing 90\% [13]. The Shh subgroup is often seen in infants younger than 3 years of age and adults over 16 years of age, but not in children [13]. Shh tumours have a similar prognosis to Group 4 tumours, between the Wnt (good prognosis) and Group 3 (poor prognosis) subgroups [13]. Less is understood about the pathways involved in Group 3 and Group 4 medulloblastoma tumours [13]. Group 3 tumours are found almost exclusively in infants and children and Group 4 tumours occur mostly in children [13]. There is significant harm associated with current treatment regimens for medulloblastoma and the patients' quality of life is particularly poor $[11,15]$. Radiation therapy is especially harmful, having significant effects on neurological, cognitive and endocrine function [15]. 
Glioblastoma multiforme accounts for $7-9 \%$ of all paediatric intracranial tumours [16], although it is the most common tumour of the CNS in adults $[4,17]$. The tumour is made up of glial cells and is particularly malignant $[18,19]$. Paediatric glioblastoma tumours are histologically identical to adult tumours; however, the underlying genetic mutations differ and therefore should be considered unique $[20,21]$. Based on morphology and clinical outcomes, there are at least 2 subtypes of glioblastoma multiforme [22]. Patients are diagnosed with primary glioblastoma if the onset of disease is quick and there were no pre-existing malignancies [22]. Secondary glioblastoma develops from an existing astrocytoma, progressing to secondary glioblastoma over a longer period of time [22]. The survival rate is grim for glioblastoma patients of all ages, having a median survival of 15 months [4], although some reports suggest that the survival rate may be slightly higher in children $[22,23]$. Complete surgical resection is difficult to achieve due to the infiltration of glioblastoma cells into normal brain tissue [24]. The tumour is often resistant to therapy and the recurrence rate is high, demonstrating the need for additional forms of treatment [17].

Ependymoma tumours comprise $\sim 10 \%$ of paediatric brain tumours, occurring predominantly in children under 3 years of age $[6,25]$. Ependymoma tumours primarily occur in the posterior fossa and are composed of radial glial cells $[6,26]$. There are two subgroups of posterior fossa $(\mathrm{PF})$ tumours: group $\mathrm{B}(\mathrm{PFB})$ tumours that occur in older children and adults and generally have a very good prognosis, and PFA tumours, which occur in infants and have a particularly dismal prognosis [26]. Ependymomas are typically chemotherapy resistant; therefore, the primary course of treatment includes maximal surgical resection of the tumour, followed by radiation therapy $[5,26,27]$. Survival rates are relatively high if the entire tumour can be removed during surgery; however, if complete surgical resection fails, long-term survival rates drop significantly from $50-75 \%$ to less than $30 \%$ [2]. Although many treatment protocols for childhood brain tumours have improved over the course of the past few decades, ependymoma therapy has not made such significant progress [26].

Atypical teratoid/rhabdoid tumour (AT/RT) is an aggressive malignancy that occurs most often in the posterior fossa [28]. AT/RT was first described in the 1980 s, before which it was commonly misdiagnosed as a primitive neuroectodermal tumour [28, 29]. AT/RT is rare, and comprises only $1-2 \%$ of paediatric brain tumour cases, with higher incidence in children less than 2 years of age [28,30,31]. The tumour is composed primarily of rhabdoid cells with or without primitive neuroepithelial, epithelial and/or mesenchymal cells [30]. Based on preliminary data, there are four major molecular subgroups of AT/RT that have recently been identified by gene expression profiling and hierarchical clustering [32]. Patient survival significantly differs between these four clusters, and the bone morphogenetic protein (BMP) pathway has been implicated in the clusters that are associated with a shorter survival time [32]. AT/RT has a particularly poor prognosis; the majority of patients succumb to the tumour within 1 year of diagnosis despite efforts of surgery, aggressive chemotherapy and/or radiation therapy $[29,31]$. Due to a lack of effective treatment regimens and very poor prognoses, there is a great necessity for novel therapies for paediatric brain tumours.

\section{Challenges of Current Treatments}

Surgery, chemotherapy and/or radiation therapy are the standard treatments for paediatric brain tumours; however, there are multiple challenges associated with the use of these therapies. Many cancer patients are immunocompromised due to the release of immunosuppressive factors from tumour cells, and chemotherapy/ radiation therapies further deplete the body of healthy blood cells $[9,33]$. Brain tumour patients in particular also experience a unique set of obstacles when considering current treatment protocols.

Surgery plays an important role in treating brain tumours; however, the intracranial location of many CNS tumours heightens the risk associated with attempts at surgical resection [7]. As a consequence, it is often not possible to completely remove the primary tumour mass, and some brain tumours are not operable [7].

The blood-brain barrier (BBB) is the interface between the blood and the brain that separates the circulating blood from the brain extracellular fluid in order to maintain homeostasis [34]. Due to the presence of this barrier, the ability of therapeutic drugs to enter the brain from the blood needs to be considered and often limits the effective chemotherapeutic options [9]. As of 2001, only one drug, temozolomide, had been approved for use in the treatment of primary brain tumours [3].

Unfortunately, many brain tumours are highly resistant to radiation and chemotherapy, and relapse is common [35]. The neurotoxicity of chemotherapeutic agents significantly limits the administered dose to patients [36]. Radiation therapy is an important part of treatment for older children and adults; however, it is particularly harmful for infants, having severe neurotoxic effects on the developing brain $[2,6]$. For example, effects on cognitive function have been observed in children treated with radiation for CNS tumours at young ages [37]. The use of aggressive chemotherapy can be effective to control the tumour until radiation therapy can be used; however, survival rates are much lower than older children treated early with radiation therapy [37].

Chemotherapeutic drugs target rapidly dividing cells and tumour cells often develop resistance to anti-cancer drugs [38]. Cancer stem cells $(\mathrm{CD} 133+)$ have a slow turnover rate and have a propensity to give rise to tumour cells [38]. These cells demonstrate a high resistance to standard treatment, particularly radiation, owing to the fact that their DNA damage repair system is extremely efficient compared to CD133tumour cells [39]. These cancer stem cells should be regarded as a crucial target of future cancer therapeutics, since they are substantial players in the maintenance of the tumour [11]. Cell-based therapies such as adoptive NK cell transfer are not dependent on the target cell cycle and therefore may be an effective means to target cancer stem cells [38].

\section{NK Cell Function in Tumour Immunosurveillance}

The immune system functions to eliminate cancerous/precancerous cells before they can divide and create disease in the host [40]. Many tumours, however, are able to develop even in the presence of an efficient host immune system. How the tumour can evade immune surveillance and establish itself is a question that is important to consider when designing cancer therapeutics.

Some cells of the adaptive immune system have natural antitumour activity [41]. Cytotoxic $\mathrm{T}$ lymphocytes (CTLs) become activated by recognition of tumour-specific peptides, presented in the context of host major histocompatibility complex class I (MHC-I) molecules on the surface of tumour cells [41]. Many advanced tumours undergo the process of immunoediting and downregulate surface expression of MHC-I as a mechanism of immune escape [41]. 
NK cells are able to detect and kill tumours that have altered MHC-I expression [42]. Due to the natural involvement of the immune system in cancer surveillance, there is on-going research into using therapeutic drugs that can increase cancer cell immunogenicity [40]. Furthermore, many studies are looking into the direct use of immune cells for targeted cellular therapy.

NK cells are major innate immune cells involved in tumour immunosurveillance. These cells have direct cytolytic activity and also secrete pro-inflammatory cytokines to recruit additional immune cells to the site $[8,40]$. Unlike CTLs, NK cells recognize a broad range of antigens and do not require previous exposure or immunization to initiate effector function [9]. The killing mechanism is similar to CTLs in that it involves the polarized release of cytolytic granules containing perforin and granzyme toward the target cell, causing the cell to undergo apoptosis [43].

NK cells do not attack healthy cells due to the interactions of inhibitory receptors such as killer immunoglobulin-like receptors (KIRs) with MHC-I on the surface of the cell $[8,9,40]$. The cytoplasmic tail of inhibitory receptors contains immunoreceptor tyrosine-based inhibitory motifs (ITIMs) that activate downstream targets [8]. These targets interfere with signalling from immunoreceptor tyrosine-based activating motifs (ITAMs) from activating receptors [8]. It is therefore a balance of inhibitory and activating signals that determines the activity of NK cells.

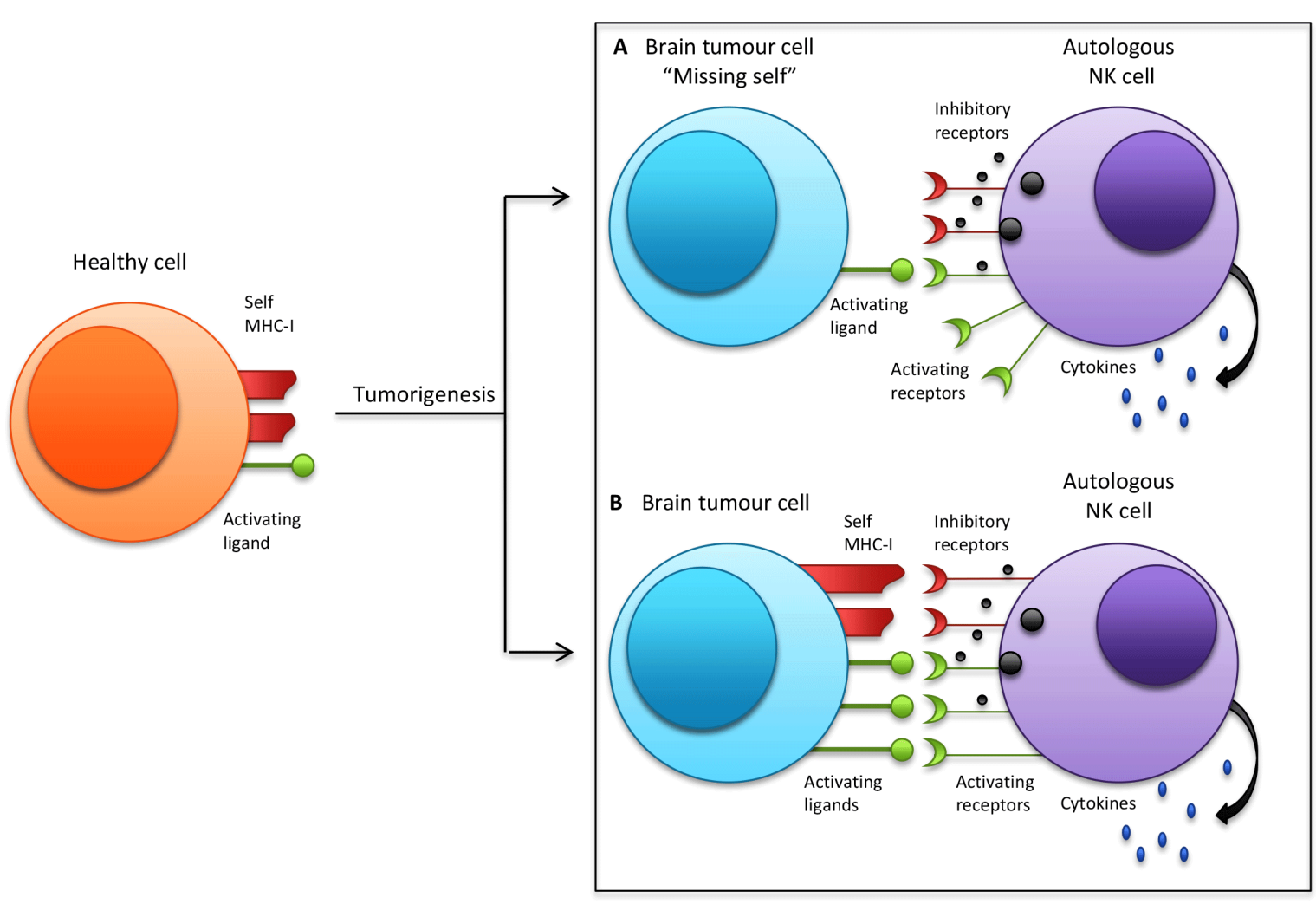

Figure 1: Mechanisms of autologous NK cell activation by paediatric brain tumour cells. Activation of NK cells results in the release of proinflammatory cytokines and cytolytic granules. In a healthy cell, interactions of self MHC-I with NK cell inhibitory receptors result in selftolerance. A Self MHC-I expression can be downregulated in some tumour cells, the absence of which lifts the natural inhibition of autologous NK cells, resulting in tumour cell lysis. B Activating ligands upregulated on tumour cells provides a strong activating signal to autologous NK cells, allowing the NK cell to overcome inhibition. Adapted from Vivier et al. and Kumar \& McNerney [42, 44].

NK cells have evolved a mechanism to recognize advanced tumours that have reduced MHC-I expression, a concept known as the 'missing self hypothesis (Figure 1A) [40-42,44]. Tumour cells are also known to upregulate the surface expression of death receptors, TRAILR and Fas, on their surface, the ligands of which can be provided by NK cells to trigger apoptosis [43].

Cytotoxic activity can be stimulated by cytokines binding to cytokine receptors on NK cells, or through the interaction of activating receptors with antigen on the surface of transformed cells [40, 45]. Cytokine receptor stimulation is known to increase the surface expression of activating receptors on NK cells [46]. The crosslinking of several activating receptors allows the NK cell to overcome its natural inhibition and initiate effector function [47]. Major activating receptors on NK cells are the natural cytotoxity receptors (NCRs), NKp46, NKp30 and NKp44, which are specific to NK cells [24]. Other important NK cell activating receptors are NKG2D and DNAM-1, which are also expressed on CTLs [24]. The ligands of these receptors are tumour-associated antigens (TAAs), which are often up-regulated on the cell membrane of many human malignancies (Figure 1B) $[8,9,42,44]$. It is clear that NK cells play an important role in the elimination of tumour cells. For example, depleting NK cells in mouse models results in an increased incidence of cancer [47]. In addition, inactivating major activating receptors such as NKG2D and DNAM-1 in mouse models is correlated with an increased incidence of tumours 
and particular NKG2D gene polymorphisms have been linked with susceptibility to cancer $[48,49]$. The natural role of NK cells in tumour surveillance demonstrates their promise as a form of therapy for cancer patients.

\section{The Immunotherapeutic Potential of NK Cells}

Immunotherapy for human tumours has been a focus of many research groups because it allows for cancerous cells to be targeted and killed, while sparing normal cells [50]. The ability of immune cells to invade the tumour site appears to be tumour specific; therefore, it is likely that the susceptibility of various brain tumours to immunotherapeutic approaches may vary [51]. A common caveat of immunotherapy comes from the idea that the CNS is immuneprivileged due to the presence of the $\mathrm{BBB}$ that limits the entry of immune cells into the brain [35,50]; however, recent research suggests that lymphocytes may be able to access the brain under pathological circumstances due to changes in the physical structure of the BBB [52].

Anti-tumour vaccines, such as peptide and cell-based vaccines are the most established among immunotherapies for cancer [35]. Dendritic cell (DC) vaccines involve the use of tumour-antigen-loaded DCs to activate host lymphocytes, since antigen presenting cells are often dysfunctional in cancer patients [35]. DC therapy integrated with radiation and chemotherapy for glioblastoma has been reported to have promising results with only mild toxicity and has been implemented in recent clinical trials [53-56]. Adoptive targeted cell therapy is a more recent strategy for treating cancers. Lymphokineactivated killer (LAK) cells are isolated from peripheral blood lymphocytes cultured with interleukin-2 (IL-2) and are composed of both CTLs and NK cells [57]. A combination of low-dose IL-2 with ex vivo IL-2 activated LAK cells infused into the surgical resection cavity of glioma patients has proven to be safe, with some toxicity to the patient including fever, headache and neurological irritation [3]. Due to the toxicity associated with IL-2 administration, CTLs that have been activated ex vivo against specific CNS tumour antigens has been examined as an alternative strategy [50]. CTL adoptive therapy has been shown to be effective, but may only be temporary for advanced cases [58]. Previous research has therefore demonstrated promise for brain tumour immunotherapy; however, most of the research to date has focussed on the use of DC, LAK cell and CTL therapy. The immunotherapeutic potential of NK cells is less well understood.

There have been a number of studies reporting the involvement of $\mathrm{NK}$ cells in the eradication of tumours in vivo. For example, CpG oligodeoxynucleotide (CpG-ODN) administration has been reported to augment NK cell activity in non-Hodgkin's lymphoma [59]. CpGODN therapy also resulted in a tumour-reduction response for acute lymphoblastic leukaemia and gliomas in mouse models [60,61]. The cytolytic function of NK cells against many human cancers in vitro has also been demonstrated. Ex vivo expanded and activated NK cells have been shown to be significantly more cytotoxic than freshly isolated NK cells, as seen for tumours such as Ewing sarcoma and rhabdomyosarcoma [62]. IL-15 activated NK cells have been shown to be effective at killing both chemotherapy sensitive and resistant osteosarcoma cell lines in vitro [46]. Adoptive NK cell therapy is therefore becoming a promising candidate for the treatment of many human tumours, with the added benefit that NK cells do not cause Graft versus Host Disease [10].
There are numerous potential uses of NK cells for immunotherapy. Systemic administration of cytokines can activate autologous NK cells; however, this method is correlated with severe side effects [63]. EX vivo cytokine activation of autologous NK cells followed by adoptive transfer back into the patient has proved to be more successful [64]. Ishikawa et al. reported the earliest human clinical trial of autologous NK cell therapy for brain tumours and showed that autologous ex vivo activated NK cells given as both intravenous and focal injections were partially effective against adult gliomas [64]. The efficacy of these ex vivo expanded and activated NK cells against gliomas was similar to high-dose IL-2 and LAK cell therapies that see a reduction in tumour mass; however, there was no severe neurotoxicity associated with NK cell therapy [64]. Unfortunately, the efficacy of autologous NK cell transfer is limited, as it is more difficult for NK cells to overcome the inhibition provided by 'self MHC-I molecules on the surface of the tumour cells (Figure 1B) [42,44,65].

Allogeneic NK cells have inhibitory KIR receptor/ligand mismatch due to the absence of 'self inhibitory ligands on tumour cells, rendering them a more desirable therapeutic candidate compared to autologous NK cells (Figure 2) [42,44,63]. Adult glioblastoma multiforme stem-like cells have been reported to be resistant to resting NK cells, but are highly susceptible to both autologous and allogeneic ex vivo IL-2 and IL-15 activated NK cells [24]. Castriconi and coworkers refuted previous reports that glioblastoma cells are resistant to NK cell-mediated killing; however, NK cell lines and resting NK cells were commonly used in place of ex vivo cytokine-activated NK cells [24]. Glioblastoma cells have low-density surface expression of MHC-I and highly express ligands of NK cell activating receptors, particularly for DNAM-1 [24]. DNAM-1 and NKp46 appear to be major players in the cytolysis of glioblastoma cells by NK cells [24].

Thirdly, NK cells participate in antibody-dependent cell-mediated cytotoxicity (ADCC) through the CD16 receptor, which binds to antibodies on target cells [63]. For example, non-Hodgkin's lymphoma is treated with the monoclonal antibody, rituximab, the elimination of which is in part mediated by NK cells [59]. In vitro, treatment of osteosarcoma patient samples with the anti-EGFR antibody, cetuximab, was found to increase the activity of NK cells by encouraging ADCC [66].

NK cell lines such as NK-92 are easily maintained in vitro and eliminate the need for donors for adoptive NK cell transfer [63]. NK-92 has proven to be safe for use in humans with mild toxicity and the cells remain in the circulation for up to 48 hours [38,67]. NK-92 is a popular cell line that lacks most inhibitory receptors while expressing a large variety of activating receptors, making the cells especially cytotoxic [38]. The NK-92 cell line has been used in clinical trials for treatment of advanced, treatment-resistant cancers. In a phase I clinical trial, Tonn et al. used NK-92 to treat 15 patients of a wide age range with both solid tumours/sarcomas and haematological malignancies such as leukaemia [38]. Infusions of NK-92 of up to $10^{10}$ cells/m2 were tested in these patients, and no major infusion-related short or long-term side effects were observed, suggesting that NK-92 is well tolerated in cancer patients [38]. NK-92 infusions demonstrated partial efficacy in some patients with end-stage cancer such as advanced renal cell cancer and melanoma [38]. 


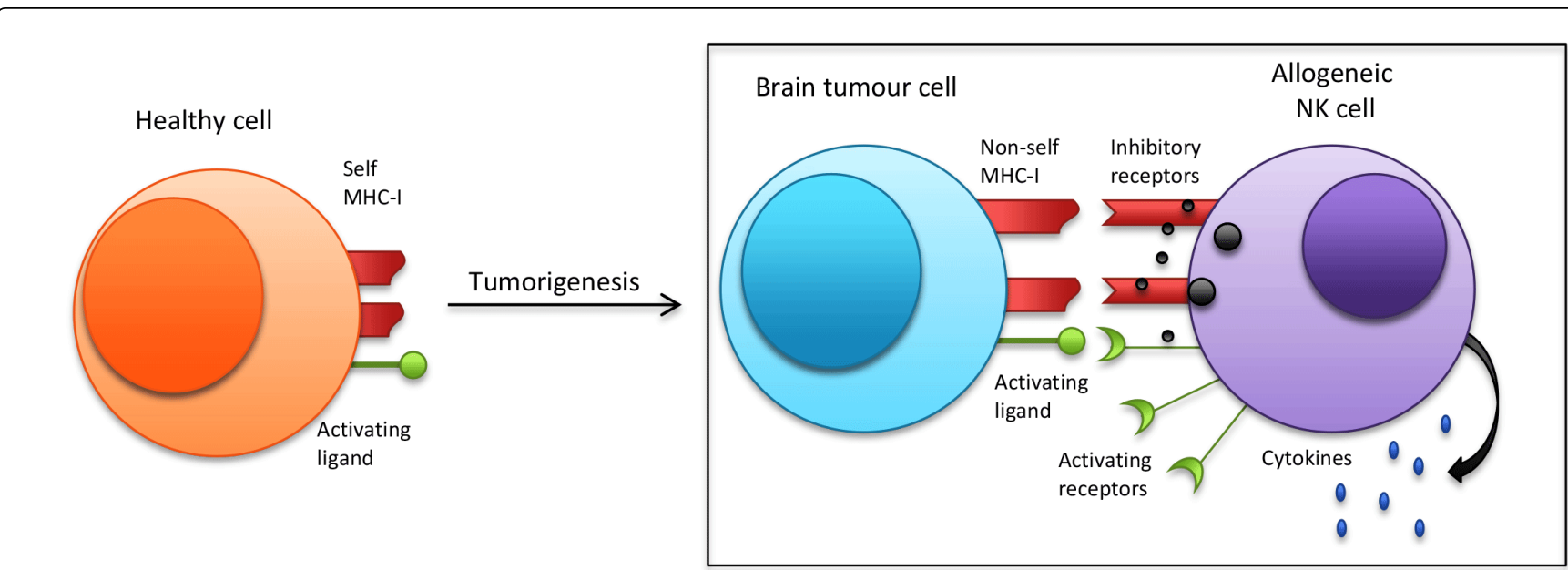

Figure 2: Allogeneic NK cells do not recognize non-self MHC-I and may easily become activated by activating ligands on paediatric brain tumour cells. Adapted from Vivier et al. and Kumar \& McNerney [42,44].

Lastly, technology such as siRNA has allowed for the manipulation of NK cell gene expression such as the downregulation of inhibitory receptors and the upregulation of activating receptors [63]. NK-92 has been genetically modified to express a chimeric antigen receptor for CD20 on previously determined NK cell-resistant lymphoma and leukaemia cells, rendering them susceptible to cytolysis [68].

Many in vitro studies have demonstrated the susceptibility of brain tumour cells to NK cells. For example, IL-2 activated NK cells are proficient in killing medulloblastoma cell lines and a primary medulloblastoma cell culture in vitro [11]. The major activating receptors involved were the natural cytotoxicity receptors, NKp46 and NKp30, as well as DNAM-1 and NKG2D, whose ligands were found to be present on the tumour cells [11]. According to Castriconi and colleagues, there were minimal inhibitory interactions between the NK cells and the medulloblastoma cells [11]. In contrast, Fernández et al. reported high MHC-I expression on 54 medulloblastoma patient tumour samples that may result in a natural resistance to NK cells [14]. The same group reported that blocking MHC-I on a medulloblastoma cell line and incubation with IL-15 activated NK cells resulted in efficient cytolysis [14]. The susceptibility of both CD133- medulloblastoma cells and CD133+ cancer stem cells to NK cell-mediated killing in vitro has been reported [11]. This observation provides an exceptional rationale for the further investigation of cellbased therapies for human malignancies. Sivori et al. showed that glioblastoma cell lines are susceptible to NK cell killing and involves the activation of natural cytotoxicity receptors [69]. Previously, it was suggested that CD16 is also involved in direct target cell recognition and activation of NK cells in addition to its role in ADCC [70]. Sivori and co-workers, however, found no difference between the cytotoxicity of $\mathrm{CD}^{+} 6^{+}$and $\mathrm{CD} 16^{-} \mathrm{NK}$ cells against glioblastoma cell lines and therefore concluded that CD16 does not play a direct cellrecognition/activation role in the clearance of neural tumour cells [69].

To date, there have been a limited number of completed clinical trials for NK cell therapy; however, there are many on-going clinical trials for their use in the treatment of various human malignancies (Table 1). Although NK cells demonstrate promise for use in cellular cancer therapy, there are limitations to its widespread use. For adoptive autologous/allogeneic NK cell therapy, NK cells must be acquired from the peripheral blood of the patient or donor respectively. Up to $10^{11}$ lymphocytes are required for cell therapy, and a significant challenge in developing an NK cell-based immunotherapy is the struggle to achieve a sufficient quantity of cells $[10,71]$. NK cells represent only a small fraction (up to 15\%) of peripheral blood lymphocytes and are difficult to expand ex vivo [10,47]. Current research is focused on discovering an optimal ex vivo expansion/ activation protocol to achieve maximal expansion rates, cytotoxicity and long-term survival of NK cells.

IL-2, IL-15 and IL-21 are all $\gamma$ chain receptor family ligands and have been demonstrated to be particularly important for NK cell activation [45]. IL-15 and IL-21 activated NK cells have similar cytotoxicity; however, IL-21 is far more effective at stimulating NK cell expansion [10]. IL-21 is the most recently described and most potent cytokine for NK cell expansion thus far [10]. Recent studies suggest that the combination of IL-12, IL-15 and IL-18 can induce long-term survival and memory in NK cells, which is desirable in the case of cancer relapse [72]. Feeder cells such as irradiated Epstein-Barr virustransformed lymphoblastic cells have been shown to induce an in vitro NK cell expansion of up to 100 -fold after 15 days, a yield far superior to cytokine-induced expansion [73]. Recently, the use of particles derived from the plasma membrane of K562 feeder cells expressing IL-15 and 4-1BBL on their surface, in addition to a low concentration of IL-2 was found to induce a 200-fold NK cell expansion of $95 \%$ purity after 12-13 days of culture [74]. This particle-based method was found to yield more reproducible results between different donors compared to live feeder cell-based protocols and resulted in highly cytotoxic NK cells [74]. Currently, trials in NSG mice are being carried out [74]. The use of artificial antigen presenting cells such as an irradiated K562-derived clone genetically engineered to express a membrane bound variant of IL-21 resulted in a 2300 -fold NK cell expansion with $83 \%$ purity after 14 days [75]. There is an on-going pursuit for an ex vivo NK cell expansion and activation protocol that will provide maximal NK cell yield, cytotoxicity, survival and memory for adoptive therapy. 


\begin{tabular}{|c|c|c|c|c|c|}
\hline Condition & Ex vivo NK Cell Activation & NK Cell Source & Trial Phase & Participant age range & $\begin{array}{l}\text { ClinicalTrials.gov } \\
\text { Identifier }\end{array}$ \\
\hline AML/MDS & IL-15 activated & Haploidentical & Phase 1 & $>18$ years & NCT01385423 \\
\hline AML & $\begin{array}{l}\text { Cytokine-induced memory-like NK } \\
\text { cells }\end{array}$ & Haploidentical & Phase 1 & $>18$ years & NCT01898793 \\
\hline AML & IL-21 activated & Haploidentical & Phase $1 / 2$ & $18-59$ years & NCT01787474 \\
\hline AML/MDS; T-cell ALL & $\begin{array}{l}\text { Irradiated K562-mb15-41BBL cells } \\
\text { and low dose }(10 \mathrm{IU} / \mathrm{mL}) \mathrm{IL}-2\end{array}$ & $\begin{array}{l}\text { Family member with at } \\
\text { least } 3 \text { of } 6 \mathrm{HLA} \text { match to } \\
\text { recipient }\end{array}$ & Phase 1 & $6-80$ years & NCT02123836 \\
\hline B-lineage ALL & $\begin{array}{l}\text { K562-mb15-41BBL and IL-2; } \\
\text { transduced with chimeric antigen } \\
\text { receptor (anti-CD19-BB-zeta) }\end{array}$ & $\begin{array}{l}\text { Family member with at } \\
\text { least } 3 \text { of } 6 \mathrm{HLA} \text { match to } \\
\text { recipient }\end{array}$ & Phase 2 & $6-80$ years & NCT01974479 \\
\hline MM & IL-2 activated & $\begin{array}{l}\text { Umbilical cord blood- } \\
\text { derived }\end{array}$ & Phase $1 / 2$ & $18-75$ years & NCT01729091 \\
\hline $\begin{array}{l}\text { Neuroblastoma post anti- } \\
\text { GD2 antibody }\end{array}$ & IL-2 activated & $\begin{array}{l}\text { Partly matched HLA family } \\
\text { member }\end{array}$ & Phase 1 & $<21$ years & NCT01576692 \\
\hline $\begin{array}{l}\text { Non-small cell lung } \\
\text { cancer stage IIIA/B }\end{array}$ & Hsp70-peptide TKD/IL-2 activated & Autologous & Phase 2 & $18-75$ years & NCT02118415 \\
\hline $\begin{array}{l}\text { Leukaemia; Lymphoma; } \\
\text { MM; HD }\end{array}$ & N/A & NK-92 cell line & Phase 1 & $>18$ years & NCT00990717 \\
\hline Various & IL-15 activated & Autologous & Phase 1 & $2-25$ years & NCT01875601 \\
\hline
\end{tabular}

Table 1: On-going clinical trials of NK cell therapy for human malignancies. Information obtained from http://www.clinicaltrials.gov/. AML: Acute Myeloid Leukaemia; MDS: Myelodysplastic Syndrome; ALL: Acute Lymphoblastic Leukaemia; MM: Multiple Myeloma; HD: Hodgkin’s Disease.

\section{Future Studies}

Paediatric brain tumour patients would benefit considerably from a novel type of therapy. It is clear that NK cells have enormous therapeutic potential for human cancers; however, research on their use for paediatric brain tumours is inadequate. Therefore, future research should be focused on discovering the immunotherapeutic potential of NK cells for paediatric brain tumours.

To the best of our knowledge, there have not been any studies to date describing the susceptibility of paediatric brain tumours, glioblastoma multiforme, ependymoma and AT/RT to NK cells. Since the prognosis of these tumours can be especially poor, these patients would benefit substantially from a novel form of therapy. NK cell ligand expression on cell lines and primary brain tumour tissue samples should be analyzed in order to determine if they may be candidates for NK cell therapy. Additionally, in vitro cytotoxicity assays should be performed in order to assess their susceptibility to NK cell-mediated killing.

As there are conflicting results as to whether or not NK cells are able to infiltrate brain tumours, humanized mouse models harbouring intracranial paediatric brain tumours should be examined, monitoring tumour size as well as NK cell localization to the brain following NK cell therapy [9].

\section{Acknowledgements}

The authors declare no conflicts of interest.

\section{References}

1. Patel S, Bhatnagar A, Wear C, Osiro S, Gabriel A, et al. (2014) Are paediatric brain tumors on the rise in the USA? Significant incidence and survival findings from the SEER database analysis. Childs Nerv Syst 30: 147-154.

2. Pollack IF (2011) Multidisciplinary management of childhood brain tumors: a review of outcomes, recent advances, and challenges. J Neurosurg Pediatr 8: 135-148.

3. Hayes RL, Arbit E, Odaimi M, Pannullo S, Scheff R, et al. (2001) Adoptive cellular immunotherapy for the treatment of malignant gliomas. Crit Rev Oncol Hematol 39: 31-42.

4. Gaspar N, Marshall L, Perryman L, Bax DA, Little SE, et al. (2010) MGMT-independent temozolomide resistance in paediatric glioblastoma cells associated with a PI3-kinase mediated HOX/stem cell gene signature. Cancer Res 70:9243-9252.

5. Willard VW, Conklin HM, Boop FA, Wu S, Merchant TE (2014) Emotional and behavioral functioning after conformal radiation therapy for paediatric ependymoma. Int J Radiat Oncol Biol Phys 88: 814-821.

6. de Bont JM, Packer RJ, Michiels EM, den Boer ML, Pieters R (2008) Biological background of paediatric medulloblastoma and ependymoma: A review from a translational research perspective. Neuro Oncol 10:1040-1060. doi:10.1215/15228517-2008-059

7. Castro MG, Cowen R, Williamson IK, David A, Jimenez-Dalmaroni MJ, et al. (2003) Current and future strategies for the treatment of malignant brain tumors. Pharmacol Ther 98: 71-108.

8. Long EO, Kim HS, Liu D, Peterson ME, Rajagopalan S (2013) Controlling natural killer cell responses: integration of signals for activation and inhibition. Annu Rev Immunol 31: 227-258.

9. Kmiecik J, Zimmer J, Chekenya M (2014) Natural killer cells in intracranial neoplasms: presence and therapeutic efficacy against brain tumours. J Neurooncol 116: 1-9. 
10. Denman CJ, Senyukov VV, Somanchi SS, Phatarpekar PV, Kopp LM, et al. (2012) Membrane-bound IL-21 promotes sustained ex vivo proliferation of human natural killer cells. PLoS One 7: e30264.

11. Castriconi R, Dondero A, Negri F, Bellora F, Nozza P, et al. (2007) Both $\mathrm{CD} 133+$ and CD133- medulloblastoma cell lines express ligands for triggering NK receptors and are susceptible to NK-mediated cytotoxicity. Eur J Immunol 37: 3190-3196.

12. Brain Tumour Foundation of Canada: Medulloblastoma.

13. Taylor MD, Northcott PA, Korshunov A, Remke M, Cho YJ, et al. (2012) Molecular subgroups of medulloblastoma: the current consensus. Acta Neuropathol 123: 465-472.

14. Fernández L, Portugal R, Valentín J, Martín R, Maxwell H, et al. (2013) In vitro Natural Killer Cell Immunotherapy for Medulloblastoma. Front Oncol 3: 94.

15. Sonabend AM, Ogden AT, Maier LM, Anderson DE, Canoll P, et al. (2012) Medulloblasoma: challenges for effective immunotherapy. Neurooncol 108: 1-10.

16. Khalatbari MR, Hamidi M, Moharamzad Y (2011) Glioblastoma multiforme with very rapid growth and long-term survival in children: report of two cases and review of the literature. Childs Nerv Syst 27: 1347-1352.

17. Chen J, Li Y, Yu TS, McKay RM, Burns DK, et al. (2012) A restricted cell population propagates glioblastoma growth after chemotherapy. Nature 488: 522-526.

18. American Association of Neurological Surgeons: Glioblastoma multiforme.

19. Farin A, Suzuki SO, Weiker M, Goldman JE, Bruce JN, et al. (2006) Transplanted glioma cells migrate and proliferate on host brain vasculature: a dynamic analysis. Glia 53: 799-808.

20. Perkins SM, Rubin JB, Leonard JR, Smyth MD, El Naqa I, et al. (2011) Glioblastoma in children: a single-institution experience. Int J Radiat Oncol Biol Phys 80: 1117-1121.

21. Rheinbay E, Louis DN, Bernstein BE, Suvà ML (2012) A tell-tail sign of chromatin: histone mutations drive paediatric glioblastoma. Cancer Cell 21: 329-331.

22. Mahvash M, Hugo HH, Maslehaty H, Mehdorn HM, Stark AM (2011) Glioblastoma multiforme in children: report of 13 cases and review of the literature. Pediatr Neurol 45: 178-180.

23. Song KS, Phi JH, Cho BK, Wang KC, Lee JY, et al. (2010) Long-term outcomes in children with glioblastoma. J Neurosurg Pediatr 6: 145-149.

24. Castriconi R, Daga A, Dondero A, Zona G, Poliani PL, et al. (2009) NK cells recognize and kill human glioblastoma cells with stem cell-like properties. J Immunol 182: 3530-3539.

25. Purdy E, Johnston DL, Bartels U, Fryer C, Carret AS, et al. (2014) Ependymoma in children under the age of 3 years: a report from the Canadian Paediatric Brain Tumour Consortium. J Neurooncol 117: 359-364.

26. Mack SC, Witt H2, Piro RM3, Gu L4, Zuyderduyn S5, et al. (2014) Epigenomic alterations define lethal CIMP-positive ependymomas of infancy. Nature 506: 445-450.

27. Johnson RA, Wright KD, Poppleton H, Mohankumar KM, Finkelstein D, et al. (2010) Cross-species genomics matches driver mutations and cell compartments to model ependymoma. Nature 466: 632-636.

28. Biswas A, Goyal S, Puri T, Das P, Sarkar C, et al. (2009) Atypical teratoid rhabdoid tumor of the brain: case series and review of literature. Childs Nerv Syst 25: 1495-1500.

29. Chi SN, Zimmerman MA, Yao X, Cohen KJ, Burger P, et al. (2009) Intensive multimodality treatment for children with newly diagnosed CNS atypical teratoid rhabdoid tumor. J Clin Oncol 27: 385-389.

30. Samaras V, Stamatelli A, Samaras E, Stergiou I, Konstantopoulou P, et al. (2009) Atypical teratoid/rhabdoid tumor of the central nervous system in an 18-year-old patient. Clin Neuropathol 28: 1-10.

31. Rorke LB, Packer RJ, Biegel JA (1996) Central nervous system atypical teratoid/rhabdoid tumors of infancy and childhood: definition of an entity. J Neurosurg 85: 56-65.
32. Birks DK, Donson AM, Patel PR, Dunham C, Muscat A, et al. (2011) High expression of BMP pathway genes distinguishes a subset of atypical teratoid/rhabdoid tumors associated with shorter survival. Neuro Oncol 13:1296-1307.

33. Sengupta S, Marrinan J, Frishman C, Sampath P (2012) Impact of temozolomide on immune response during malignant glioma chemotherapy. Clin Dev Immunol 2012: 831090.

34. Leshan R, Milner T, Pfaff DW (2013) Blood Brain Barrier. In: Pfaff DW (ed) Neuroscience in the 21st Century From Basic to Clinical. Springer, New York, 1621-1629.

35. Jackson CM, Lim M, Drake CG (2014) Immunotherapy for brain cancer: recent progress and future promise. Clin Cancer Res 20: 3651-3659.

36. Verstappen CC, Heimans JJ, Hoekman K, Postma TJ (2003) Neurotoxic complications of chemotherapy in patients with cancer: clinical signs and optimal management. Drugs 63: 1549-1563.

37. Geyer JR, Sposto R, Jennings M, Boyett JM, Axtell RA, et al. (2005) Multiagent chemotherapy and deferred radiotherapy in infants with malignant brain tumors: a report from the Children's Cancer Group. J Clin Oncol 23: 7621-7631.

38. Tonn T, Schwabe D, Klingemann HG, Becker S, Esser R, et al. (2013) Treatment of patients with advanced cancer with the natural killer cell line NK-92. Cytotherapy 15: 1563-1570.

39. Bielamowicz K, Khawja S, Ahmed N (2013) Adoptive cell therapies for glioblastoma. Front Oncol 3: 275.

40. Chan CJ, Smyth MJ, Martinet L (2014) Molecular mechanisms of natural killer cell activation in response to cellular stress. Cell Death Differ 21: 5-14.

41. Gomes AQ, Correia DV, Silva-Santos B (2007) Non-classical major histocompatibility complex proteins as determinants of tumour immunosurveillance. EMBO Rep 8: 1024-1030.

42. Kumar V, McNerney ME (2005) A new self: MHC-class-I-independent natural-killer-cell self-tolerance. Nat Rev Immunol 5: 363-374.

43. Cheng M, Chen Y, Xiao W, Sun R, Tian Z (2013) NK cell-based immunotherapy for malignant diseases. Cell Mol Immunol 10: 230-252.

44. Vivier E, Ugolini S, Blaise D, Chabannon C, Brossay L (2012) Targeting natural killer cells and natural killer T cells in cancer. Nat Rev Immunol 12: $239-252$

45. de Rham C, Ferrari-Lacraz S, Jendly S, Schneiter G, Dayer JM, et al. (2007) The proinflammatory cytokines IL-2, IL-15 and IL-21 modulate the repertoire of mature human natural killer cell receptors. Arthritis Res Ther 9: R125.

46. Buddingh EP, Schilham MW, Ruslan EN, Berghuis D, Szuhai K, et al. (2011) Chemotherapy-resistant osteosarcoma is highly susceptible to IL-15-activated allogeneic and autologous NK cells. Cancer Immunol Immunother 60:575-586.

47. Cerwenka A, Lanier LL (2001) Natural killer cells, viruses and cancer. Nat Rev Immunol 1: 41-49.

48. Guerra N, Tan YX, Joncker NT, Choy A, Gallardo F, et al. (2008) NKG2D-deficient mice are defective in tumor surveillance in models of spontaneous malignancy. Immunity 28: 571-580.

49. Hayashi T, Imai K, Morishita Y, Hayashi I, Kusunoki Y, et al. (2006) Identification of the NKG2D haplotypes associated with natural cytotoxic activity of peripheral blood lymphocytes and cancer immunosurveillance. Cancer Res 66: 563-570.

50. Badhiwala J, Decker WK, Berens ME, Bhardwaj RD (2013) Clinical trials in cellular immunotherapy for brain/CNS tumors. Expert Rev Neurother 13: $405-424$.

51. Griesinger AM, Donson AM, Foreman NK (2014) Immunotherapeutic implications of the immunophenotype of paediatric brain tumors. Oncoimmunology 3: e27256.

52. Dunn GP, Dunn IF, Curry WT (2007) Focus on TILs: Prognostic significance of tumor infiltrating lymphocytes in human glioma. Cancer Immun 7: 12.

53. Ardon H, Van Gool SW, Verschuere T, Maes W, Fieuws S, et al. (2012) Integration of autologous dendritic cell-based immunotherapy in the 
standard of care treatment for patients with newly diagnosed glioblastoma: results of the HGG-2006 phaseI/II trial. Cancer Immunol Immunother 61:2033-2044.

54. Ardon H, Van Gool S, Lopes IS, Maes W, Sciot R, et al. (2010) Integration of autologous dendritic cell-based immunotherapy in the primary treatment for patients with newly diagnosed glioblastoma multiforme: a pilot study. J Neurooncol 99:261-272.

55. De Vleeschouwer S, Fieuws S, Rutkowski S, Van Calenbergh F, Van Loon J, et al. (2008) Postoperative adjuvant dendritic cell-based immunotherapy in patients with relapsed glioblastoma multiforme. Clin Cancer Res 14: 3098-3104.

56. Wheeler CJ, Black KL, Liu G, Mazer M, Zhang X, et al. (2008) Vaccination elicits correlated immune and clinical responses in glioblastoma multiforme patients. Cancer Res 68:5955-5964.

57. Wilson TJ, Candolfi M, Assi H, Ayala MM, Mineharu Y, et al. (2014) Immunotherapies for brain cancer: From preclinical models to human trials. In: Hayat MA (ed) Tumors of the Central Nervous System. Springer Netherlands: 239-251.

58. Tsuboi K, Saijo K, Ishikawa E, Tsurushima H, Takano S, et al. (2003) Effects of local injection of ex vivo expanded autologous tumor-specific $\mathrm{T}$ lymphocytes in cases with recurrent malignant gliomas. Clin Cancer Res 9: 3294-3302.

59. Betting DJ, Yamada RE, Kafi K, Said J, van Rooijen N, et al. (2009) Intratumoral but not systemic delivery of $\mathrm{CpG}$ oligodeoxynucleotide augments the efficacy of anti-CD20 monoclonal antibody therapy against B cell lymphoma. J Immunother 32: 622-631.

60. Fujii H, Trudeau JD, Teachey DT, Fish JD, Grupp SA, et al. (2007) In vivo control of acute lymphoblastic leukaemia by immunostimulatory CpG oligonucleotides. Blood 109: 2008-2013.

61. Alizadeh D, Zhang L, Brown CE, Farrukh O, Jensen MC, et al. (2010) Induction of anti-glioma natural killer cell response following multiple low-dose intracerebral CpG therapy. Clin Cancer Res 16: 3399-3408.

62. Cho D, Shook DR, Shimasaki N, Chang YH, Fujisaki H, et al. (2010) Cytotoxicity of activated natural killer cells against paediatric solid tumors. Clin Cancer Res 16: 3901-3909.

63. Sta Maria NS, Barnes SR, Jacobs RE (2014) In vivo monitoring of natural killer cell trafficking during tumor immunotherapy. Magn Reson Insights 7: 15-21.

64. Ishikawa E, Tsuboi K, Saijo K, Harada H, Takano S, et al. (2004) Autologous natural killer cell therapy for human recurrent malignant glioma. Anticancer Res 24: 1861-1871.
65. Miller JS, Rooney CM, Curtsinger J, McElmurry R, McCullar V, et al. (2014) Expansion and homing of adoptively transferred human natural killer cells in immunodeficient mice varies with product preparation and in vivo cytokine administration: Implications for clinical therapy. Biol Blood Marrow Transplant 20:1238-1257.

66. Pahl JH, Ruslan SE, Buddingh EP, Santos SJ, Szuhai K, et al. (2012) AntiEGFR antibody cetuximab enhances the cytolytic activity of natural killer cells toward osteosarcoma. Clin Cancer Res 18: 432-441.

67. Arai S, Meagher R, Swearingen M, Myint H, Rich E, et al. (2008) Infusion of the allogeneic cell line NK-92 in patients with advanced renal cell cancer or melanoma: a phase I trial. Cytotherapy 10: 625-632.

68. Müller T, Uherek C, Maki G, Chow KU, Schimpf A, et al. (2008) Expression of a CD20-specific chimeric antigen receptor enhances cytotoxic activity of NK cells and overcomes NK-resistance of lymphoma and leukaemia cells. Cancer Immunol Immunother 57: 411-423.

69. Sivori S, Parolini S, Marcenaro E, Castriconi R, Pende D, et al. (2000) Involvement of natural cytotoxicity receptors in human natural killer cell-mediated lysis of neuroblastoma and glioblastoma cell lines. J Neuroimmunol 107: 220-225.

70. Mandelboim O, Malik P, Davis DM, Jo CH, Boyson JE, et al. (1999) Human CD16 as a lysis receptor mediating direct natural killer cell cytotoxicity. Proc Natl Acad Sci U S A 96: 5640-5644.

71. Galluzzi L, Vacchelli E, Eggermont A, Fridman WH, Galon J, et al. (2012) Trial Watch: Adoptive cell transfer immunotherapy. Oncoimmunology 1: 306-315.

72. Leong JW, Chase JM, Romee R, Schneider SE, Sullivan RP, et al. (2014) Preactivation with IL-12, IL-15, and IL-18 induces CD25 and a functional high-affinity IL-2 receptor on human cytokine-induced memory-like natural killer cells. Biol Blood Marrow Transplant 20: 463-473.

73. Berg M, Lundqvist A, McCoy PJ, Samsel L, Fan Y, et al. (2009) Clinicalgrade ex vivo-expanded human natural killer cells up-regulate activating receptors and death receptor ligands and have enhanced cytolytic activity against tumor cells. Cytotherapy 11:341-355.

74. Oyer J, Robert IY, Dominic C, Solh MM, Khaled Y, et al. (2013) Generation of clinical grade, highly cytotoxic NK cells using feeder cell free, particle-based technology. Blood 122:4503.

75. Liu Y, Wu HW, Sheard MA, Sposto R, Somanchi SS, et al. (2013) Growth and activation of natural killer cells ex vivo from children with neuroblastoma for adoptive cell therapy. Clin Cancer Res 19: 2132-2143. 